\title{
The Complete Nucleotide Sequence of a Korean Isolate Bean yellow mosaic virus from Freesia sp. and Comparison to Other Potyviruses
}

\author{
Sun-Hee Choi ${ }^{1 \dagger}$, Ju-Yeon Yoon $^{1 \dagger}$, Ki-Hyun Ryu ${ }^{1}$ and Seung-Kook Choi ${ }^{2 *}$ \\ ${ }^{1}$ Department of Horticulture and Landscape, College of Natural Science, Seoul Women's University, \\ Seoul 139-774, Korea \\ ${ }^{2}$ Virology Unit, Department of Horticultural Environment, National Institute of Horticultural and Herbal Science, \\ Rural Development Administration, Suwon 441-440, Korea \\ (Received on April 1, 2013; Revised on April 22, 2013; Accepted on May 2, 2013)
}

\begin{abstract}
Bean yellow mosaic virus (BYMV; genus Potyvirus, family Potyviridae) causes severe losses to various legume species and a number of non-legume species, particularly freesia plants. In a survey of virus diseases in Gyeonggi province, Korea, BYMV isolates were identified from many cultivated freesia species. Here, we determined the complete nucleotide sequences of a BYMV freesia isolate (BYMV-Fr; accession number FJ492961). BYMV-Fr genome consists of 9,545 nucleotides (nt) excluding the poly (A) tail and encodes 3,057 amino acid (aa), with an AUG start and UAG stop codon, containing one open reading frame typical of a potyvirus polyprotein. The polyprotein of BYMV-Fr was divided to ten proteins and the cleavage sites of each protein were determined. The coat protein (CP) and polyprotein of BYMV-Fr were compared at the aa level with those of the previously reported 4 BYMV isolates. BYMV-Fr shared 90.1 to 97.1 and 91.0 to $92.5 \%$ at the CP and polyprotein homology. Interestingly, BYMV-Fr showed identities of a lower level at the nt level of 5' noncoding region (61.4 to $67.6 \%$ ) and at the aa level of P1 $(71.4$ to $72.8 \%)$, comparing with four BYMV isolates. Based on the aa sequence diversity of $\mathrm{CP}$ and polyprotein, phylogenetic analysis with the four BYMV isolates showed two distinct groups and BYMV-Fr and most BYMV isolates were most closely related to the clover yellow vein virus among 52 potyviruses. To our knowledge, this is the first report of the complete genome sequence of BYMV freesia strain.
\end{abstract}

Keywords : Bean yellow mosaic virus, Freesia, Genetic diversity, Potyvirus, RT-PCR, Sequence analysis

\section{Introduction}

Freesia is a small genus of southern African Iridaceae subfamily Ixioideae, which has been familiar to horticulturists and valued by them for the beauty and fragrance of the flowers. Freesia was first grown in Europe in the mid-18th century and become one of the most popular plants in horticulture in the last half of the 19th century. Appealing shapers of freesias make them suitable line flowering for any arrangement, and their wide range of color increases their versatility (Wang, 2006), resulting that freesias are excellent cut flowers. The flowers are popular used for weddings and make fragrant additions to bouquets and body flowers. Freesias are known to be infected by Bean yellow mosaic virus

*Corresponding author

Phone) +82-31-290-6236, Fax) +82-31-290-6259

Email) viroid73@gmail.com

"These authors equally contributed to this study
(BYMV), Freesia mosaic virus, Cucumber mosaic virus, Tobacco rattle virus and ophioviruses (Brunt, 1995; Vaira et al., 2006).

BYMV belongs to the genus Potyvirus in the family Potyviridae and the virus is distributed worldwide (Bos, 1970). In comparison with the majority of potyviruses, BYMV has a relatively broad range of plant species. BYMV infects beans, peas, lupins, clovers and dicotyledonous ornamental crops such as gladiolus, bulbous iris, gentians, and some orchids. In particular, BYMV severely affects plant growth, yield and quality of flowers and corms in freesias (Derks et al., 1980; Magie and Poe, 1972). Many isolates of BYMV are recognized and have been divided into a BYMV subgroup along with the closely related potyviruses on the basis of their overlapping host ranges and common biological and immunological properties (Guyatt et al., 1996; Randles et al., 1980). BYMV virions are flexuous filamentous particles, approximately $750 \mathrm{~nm}$ in length and $15 \mathrm{~nm}$ in diameter. BYMV contains a single molecule 
of linear, positive-sense, single-stranded ribonucleic acid (ssRNA), about $9.6 \mathrm{~kb}$ in size, which has a poly (A) tract at the 3'-end (Shukla et al., 1994). Based on the results of some studies (Chang et al., 1988a; 1988b), BYMV genome is initially translated into a single polyprotein which is processed by viral-encoded proteases into its mature functional products. This gene expression strategy is defined as a general scheme of potyviral gene expression based on the analyses of other members in the genus Potyvirus (Allison et al., 1986; Dougherty et al., 1989; Shukla et al., 1994; Vance et al., 1992).

Although the genetic variability in the 3 ' noncoding region (NCR) has been correlated significantly with flowering plant origin of isolates (Wada et al., 2000), the most useful open reading frame of potyviral genome is the coat protein $(\mathrm{CP})$ gene for taxonomic analysis of BYMV isolates (Ganesh-Selvaraj et al., 2009; Hammond and Hammond, 2003; Kumar et al., 2009; Parrella and Lanave, 2009). The symptom determinants of BYMV have been assumed to localize in the N-terminal part of the $\mathrm{CP}$, one of the most hypervariable regions of the potyvirus genome (Shulka et al., 1988). While complete nucleotide sequences of $7 \mathrm{BYMV}$ isolates have been published and/or deposited with Genbank database, all of the BYMV isolates were originated from bean species or gladiolus plants. So, little is known about the complete genome sequences of BYMV isolates originated from freesia species. In this study, we report the complete nucleotide sequence of BYMV-Fr (a freesia isolate) and compare it to the sequences of BYMV isolates and other potyviruses.

\section{Materials and Methods}

Virus Source. In a disease survey of Freesia spp. in Gyeonggi-do, plants were found to show chlorotic spots, yellowing, mottling, mosaic symptoms, and necrosis on leaves of freesia plants. A total of 50 symptomatic leaf samples of Freesia spp. were collected from different farms and subjected to indirect enzyme-linked sorbent assay (ELISA) using Potyvirus-specific antisera (Agdia, USA), according to manufacturer's instruction. In brief, leaf tissues were homogenized in $100 \mathrm{mM}$ phosphate buffer containing $0.02 \% \mathrm{NaN}_{3}, 0.1 \%$ Tween 20 , and $0.1 \%$ skim milk powder ( $\mathrm{pH} 7.4$ ) at a sampleto-buffer ratio of $1: 3(\mathrm{w}: \mathrm{v})$, and $100 \mu \mathrm{l}$ of extracted sap was loaded in duplicate onto micro-titer plates. The primary antibody specific to BYMV purchased from Agdia (USA) was diluted to 1:100 in carbonate buffer (0.05 M sodium carbonate, $\mathrm{pH}$ 9.6) and the diluted antibody solution $(1 \mu \mathrm{g} / \mathrm{ml})$ was used for BYMV detection in microtiter plates. Subsequently, goat anti-rabbit IgGconjugated alkaline phosphatase was used as a secondary antibody, according to the manufacturer's instructions (Promega, USA). Substrate, 4-nitrophenyl phosphate $(0.6 \mathrm{mg} / \mathrm{ml})$, was allowed to react at room temperature for $1 \mathrm{~h}$ (Sigma, USA). Absorbance values $\left(\mathrm{A}_{405} \mathrm{~nm}\right)$ of four times the healthy control reading were used as the positive threshold. A BYMV isolate (named BYMV-Fr) selected was further confirmed by a biological method with soybean cultivars as indicator plants by mechanical inoculation.

RT-PCR and Cloning. One $\mathrm{mg}$ of leaf tissue of infected freesia was frozen in liquid $\mathrm{N}_{2}$ and ground to a fine powder. Total RNA was extracted using an RNeasy plant mini-kit, according to the manufacturer's instructions (Qiagen, USA). Total RNA containing genomic RNA of BYMV-Fr was reverse-transcribed using SuperScript $\mathrm{III}^{\circledR}$ reverse transcriptase (Invitrogen, USA) and the first cDNA was amplified using the oligonucleotide primers

Table 1. Primer sequences for the cDNA amplification of BYMV-Fr genomic RNA in this study

\begin{tabular}{|c|c|c|c|c|}
\hline Name & Directions & Position & Primer sequences $\left(5^{\prime} \rightarrow 3^{\prime}\right)$ & Size (bp) \\
\hline \multirow{2}{*}{ BY-1 } & For & $1-21$ & AAAAAATATA AAAACTAAACA & \multirow{2}{*}{1,800} \\
\hline & Rev & $1780-1800$ & ATCAATCTTCCTATAGCTAAC & \\
\hline \multirow{2}{*}{ BY-2 } & For & $1681-1702$ & CCATGCTAAGCGATTTCTTAGC & \multirow{2}{*}{1,680} \\
\hline & Rev & $3340-3360$ & GTTGGTTTTTCATTATCCCAG & \\
\hline \multirow{2}{*}{ BY-3 } & For & $3261-3281$ & TTAATGAAGCTAGGAGGATAG & \multirow{2}{*}{1,540} \\
\hline & Rev & $4778-4800$ & GGTAATCCATACGCAAAACAGTA & \\
\hline \multirow{2}{*}{ BY-4 } & For & $4718-4741$ & GGTGTAACTGAAAAAGGATTGATG & \multirow{2}{*}{1,613} \\
\hline & Rev & $6307-6330$ & TTGTTTGTTAGAAAACGAATCAGC & \\
\hline \multirow{2}{*}{ BY-5 } & For & $6250-6270$ & TGAGAGTCTCAGCAAGATAGG & \multirow{2}{*}{1,723} \\
\hline & Rev & $7951-7972$ & ATAATAAACTGCCATAATAACC & \\
\hline \multirow{2}{*}{ BY-6 } & For & $7901-7921$ & AAAGGGAATAACAGTGGACAG & \multirow{2}{*}{1,632} \\
\hline & Rev & $9513-9532$ & CTCGCTCTACAAAGATCAGG & \\
\hline
\end{tabular}


summarized in Table 1. The primers were designed from the sequences of BYMV-GDD (AY192568) and BYMV-GB2 (AB079888). The Platinum ${ }^{\circledR}$ High-fidelity PCR amplification kit (Invitrogen, USA) was used to amplify each of cDNAs to cover the full-length genomic RNA of BYMV-Fr using a pairing set of primers (Table 1). The thermo-cycling conditions for all PCR amplifications were as follows: $3 \mathrm{~min}$ at $95^{\circ} \mathrm{C}$ ( 1 cycle), $94^{\circ} \mathrm{C}$, $30 \mathrm{sec}, 55^{\circ} \mathrm{C}, 30 \mathrm{sec}$ and $72^{\circ} \mathrm{C}, 2 \mathrm{~min}$ (35 cycles), and a final extension at $72^{\circ} \mathrm{C}$ for $10 \mathrm{~min}$. The synthesized RT-PCR products were purified using Qiaquick PCR purification (Qiagen, USA) and cloned into pGEM-T easy vector (Promega, USA), according to the manufacturer' instructions.

Cloning and sequence analysis. All RT-PCR fragments were sequenced using the Big-Dye Terminator Sequencing Kit (Applied Biosystems, USA), according to the manufacturer's instructions. The complete genome sequence of BYMV-Fr determined has been deposited in the NCBI GenBank database (accession number FJ492961). Analysis of the nucleotide (nt) and deduced amino acid (aa) sequences were done using BLAST search, the DNAMAN sequence analysis software (version 5.1, Lynnon Biosoft Co. Canada) and DNASTAR software (USA). For comparison, the genome sequences of 52 representative members of the genus Potyvirus in the GenBank database were added to the genome sequence of BYMV-Fr. Nt sequence identities were calculated using the Jukes and Cantor index and genetic diversity at synonymous positions was estimated using the Hasegawa-Kishino-Yano model in the MEGA 5.0 Software (Tamura et al., 2011). Basically, phylogenetic tree analysis with BYMV CP aa or polyprotein was constructed using Neighbor-Joining with Jukes and Cantor index or
Hasegawa-Kishino-Yano model in the MEGA 5.0 software, DNAMAN, and DNASTAR software. Bootstrap analyses with 1000 replicates were performed to evaluate the significance of the interior branches.

\section{Results and Discussion}

Of 50 samples tested, 45 samples showed positive reactions in the ELISA (data not shown) when absorbance values $\left(\mathrm{A}_{405} \mathrm{~nm}\right)$ of four times the healthy control reading were used as the positive threshold. These results suggest that many freesia plants cultivated are infected by BYMV, freesia mosaic virus and other potyviruses. Of 45 potyvirus-infected samples, BYMVFr was isolated using soybean cultivars susceptible only for BYMV. To exclude the contamination of another potyvirus that can infect soybean cultivars, we further analyzed the virus-infected soybeans and freesia sample with RT-PCR amplification highly specific to BYMV CP gene and other potyviruses infecting soybean cultivars (data not shown), respectively. These results confirmed that BYMV-Fr alone infected the freesia sample and soybean cultivars.

To determine the complete genome sequence of BYMV-Fr, various sizes of cDNA fragments covering the entire genome of BYMV-Fr were amplified with primer sets shown in Table 1 and sequenced. The complete sequence of BYMV-Fr is 9,545 nt with 202 nt at the $5^{\prime} \mathrm{NCR}$ and $173 \mathrm{nt}$ at the $3{ }^{\prime} \mathrm{NCR}$ (Fig. 1) excluding the poly (A) tail. The viral genome encodes 3,057 aa with an AUG start and UAG stop codon, containing one open reading frame typical of a potyvirus polyprotein (Fig. 1). The polyprotein of BYMV-Fr is further digested into ten proteins (P1, HC-pro, P3, 6K1,

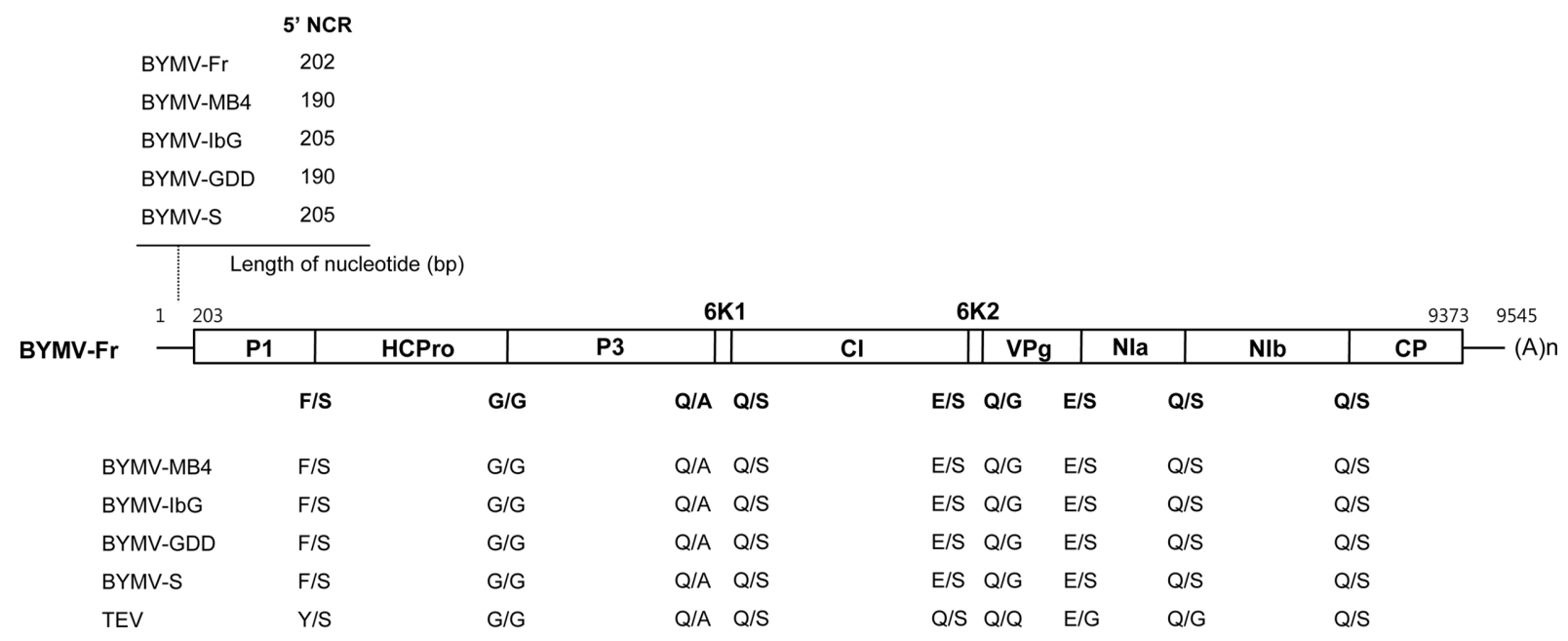

Fig. 1. The predicted genome organization of BYMV-Fr and the amino acid cleavage sites compared with those of 4 BYMV isolates and tobacco etch virus published previously. The number of nucleotides in 5'NCR was indicated on the schematic genome of BYMV-Fr. 


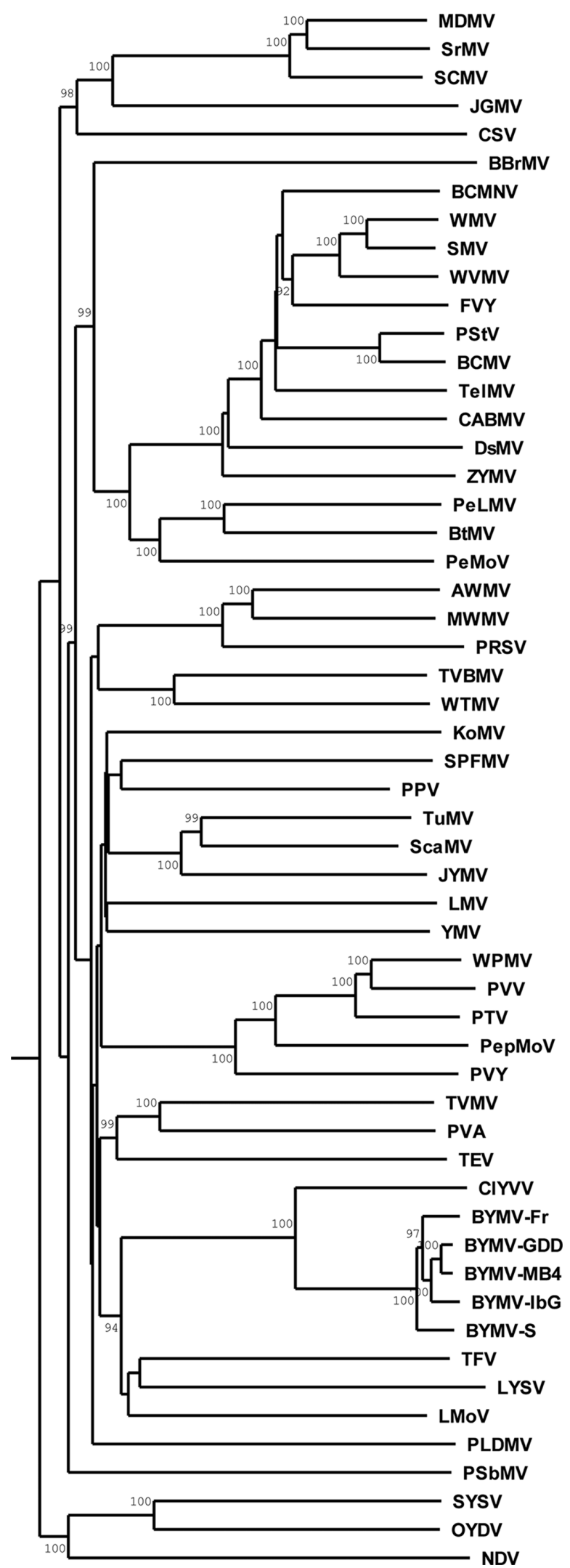

Fig. 2. Rooted trees showing the phylogenetic relationship of 52 potyviruses based on amino acid sequences of the polyproteins. Multiple sequence alignments were generated using the DNAMAN package, and the trees were constructed by the neighbor-joining algorithm based on calculations from pairwise amino acid sequence distances. The horizontal branch lengths are proportional to the genetic distance, and numbers shown at branch point indicate bootstrap values. The data set was subjected to 1,000 bootstrap replicates. Sequences of potyviruses for comparisons were obtained from the GenBank Database: bean common necrosis virus (BCMNV), NC 004047; bean common mosaic virus (BCMV), NC_003397; beet mosaic virus (BtMV), NC_005304; bean yellow mosaic virus (BYMV-MB4), D83749, BYMV-IbG (AB079887), BYMV-GDD(AY192568), BYMVS (U47033), BYMV-Fr (FJ492961, this study); cowpea aphid-borne mosaic virus (CABMV), NC 004013; chilli veinal mottle virus (ChiVMV), NC 005778; clover yellow vein virus (CIYVV), $\mathrm{NC}_{-}$ 003536; cocksfoot streak virus (CSV), NC_003742; dasheen mosaic virus (DsMV), NC_003537; daphne virus Y (DVY), NC_008028; Johnsongrass mosaic virus (JGMV), NC_003606; Japanese yam mosaic virus (JYMV), NC_000947; konja $\bar{k}$ mosaic virus (KoMV), NC_007913; lettuce mosaic virus (LMV), NC_0035605; lilly mottle virus (LMoV), NC_005288; leek yellow stripe virus (LYSV), NC 004011; maize dwarf mosaic virus (MDMV), NC_003377; onion yellow dwarf virus (OYDV), NC_005029; peanut mottle virus (PeMoV), NC_002600; Pennisetum mosaic virus (PeMV), NC_ 007147; pepper mottle virus (PepMoV), NC_001517; pepper severe mosaic virus (PepSMV), AM181350; papaya leaf distortion mosaic virus (PLDMV), NC_005028; plum pox virus (PPV), NC_001445; papaya ringspot virus (PRSV), NC_001785; pea seed-borne mosaic virus (PSbMV), NC 001671; peanut stripe virus (PStV), U34972; Peru tomato mosaic virus (PTV), NC_004573; potato virus A (PVA), NC 004039; potato virus $V$ (PVV), NC 005010; potato virus $Y$ (PVY), NC_001616, scallion mosaic virus (ScaMV), NC_003399; sugarcane mosaic virus (SCMV), NC_003398; soybean mosaic virus (SMV), NC 002634; sweet potato feathery mottle virus (SPFMV), NC_001841; sorghum mosaic virus (SrMV), NC_004035; shallot yellow stripe virus (SYSV), NC_007433; tobacco etch virus (TEV), NC 001555; tobacco vein bending mosaic virus (TVBMV), NC_009994; Thunberg fritillary virus (TFV), NC_007180; turnip mosaic virus (TuMV), NC 002509; tobacco vein mottling virus (TVMV), NC_001768; watermelon mosaic virus (WMV), NC_ 006262; wild potato mosaic virus (WPMV), NC 004426; wisteria vein mosaic virus (WiVMV), NC_007216; yam mosaic virus (YMV), NC_004752; zucchini yellow mosaic virus (ZYMV), NC_003224. 


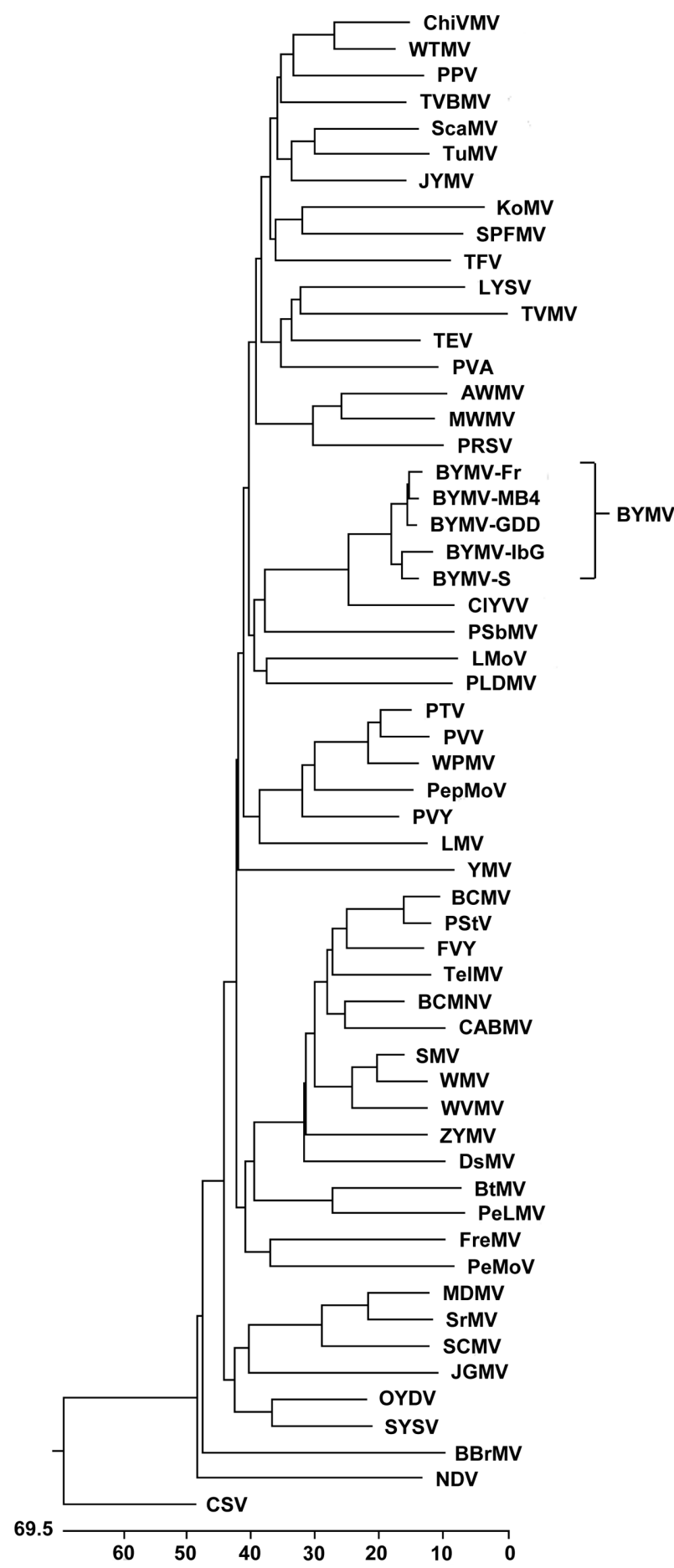

Fig. 3. Rooted trees showing the phylogenetic relationship of 52 potyviruses based on amino acid sequences of the coat proteins. Multiple sequence alignments were generated using the DNAMAN package, and the trees were constructed by the neighbor-joining algorithm based on calculations from pairwise amino acid sequence distances. The horizontal branch lengths are proportional to the genetic distance, and numbers shown at branch point indicate bootstrap values. The data set was subjected to 1,000 bootstrap replicates. Sequences of potyviruses for comparisons were obtained from the GenBank Database: bean common necrosis virus (BCMNV), NC_004047; bean common mosaic virus (BCMV), NC 003397; beet mosaic virus (BtMV), NC_005304; bean yellow mosaic virus (BYMV-MB4), D83749, BYMV-IbG (AB079887), BYMV-GDD(AY192568), BYMVS (U47033), BYMV-Fr (FJ492961, this study); cowpea aphid-borne mosaic virus (CABMV), NC_004013; chilli veinal mottle virus (ChiVMV), NC_005778; clover yellow vein virus (CIYVV), NC 003536; cocksfoot streak virus (CSV), NC_003742; dasheen mosaic virus (DsMV), NC 003537; daphne virus Y (DVY), NC 008028; Johnsongrass mosaic virus (JGMV), NC_003606; Japanese yam mosaic virus (JYMV), NC_000947; konjak mosaic virus (KoMV), NC 007913; lettuce mosaic virus (LMV), NC 0035605; lilly mottle virus (LMoV), NC_005288; leek yellow stripe virus (LYSV), NC_ 004011; maize dwärf mosaic virus (MDMV), NC 003377; onion yellow dwarf virus (OYDV), NC 005029; peanut mottle virus (PeMoV), NC_002600; Pennisetum mosaic virus (PeMV), NC_ 007147; pepper mottle virus (PepMoV), NC 001517; pepper severe mosaic virus (PepSMV), AM181350; papaya leaf distortion mosaic virus (PLDMV), NC 005028; plum pox virus (PPV), NC 001445; papaya ringspot virus (PRSV), NC_001785; pea seed-borne mosaic virus (PSbMV), NC_001671; peanut stripe virus (PStV), U34972; Peru tomato mosaic virus (PTV), NC 004573; potato virus A (PVA), NC_004039; potato virus $V$ (PVV), NC_005010; potato virus $Y$ (PVY), NC 001616, scallion mosaic virus (ScaMV), NC 003399; sugarcane mosaic virus (SCMV), NC_003398; soybean mosaic virus (SMV), NC_002634; sweet potato feathery mottle virus (SPFMV), NC 001841; sorghum mosaic virus (SrMV), NC 004035; shallot yellow stripe virus (SYSV), NC_007433; tobacco etch virus (TEV), NC 001555; tobacco vein bending mosaic virus (TVBMV), NC 009994; Thunberg fritillary virus (TFV), NC_007180; turnip mosaic virus (TuMV), NC_002509; tobacco vein mottling virus (TVMV), NC 001768; watermelon mosaic virus (WMV), NC 006262; wild potato mosaic virus (WPMV), NC_004426; wisteria vein mosaic virus (WiVMV), NC_007216; yam mosaic virus (YMV), NC_004752; zucchini yellow mosaic virus (ZYMV), NC_003224.
$\mathrm{CI}, 6 \mathrm{~K} 2, \mathrm{VPg}, \mathrm{NIa}, \mathrm{NIb}$ and $\mathrm{CP}$ ), and the cleavage sites of each protein were determined (Fig. 1). BYMVFr has a specific potyviral GDD motif in the NIb region (Urcuqui-Inchima et al., 2001) associated with viral RNA replication, a DAG motif in the $\mathrm{CP}$ region associated with aphid transmission (Lopez-Moya et al., 1999) and a FRNK motif in the HC-pro region associated with symptom expression (Gal-On, 2000).

The aa sequences of the polyprotein of VYMV-Fr whose $\mathrm{N}$ and C-termini are defined by the proteolytic cleavage sites shown in Fig. 1, were compared with the aa sequences of the corresponding polyproteins of other fully sequenced BYMV isolates and the P1, HCpro, $\mathrm{P} 3,6 \mathrm{~K} 1, \mathrm{CI}, 6 \mathrm{~K} 2, \mathrm{VPg}, \mathrm{NIa}, \mathrm{NIb}$ and $\mathrm{CP}$ of the 
Table 2. Nucleotide and amino acid sequence identity between BYMV-Fr and other isolates

\begin{tabular}{lcccccccccccc}
\hline \hline \multicolumn{1}{c}{ Isolate $^{\mathrm{a}}$} & $5^{\prime}$ NCR & P1 & HCPro & P3 & 6K1 & CI & 6K2 & VPg & NIa & NIb & CP & 3' NCR \\
\hline BYMV-MB4 & \multirow{2}{*}{$67.6^{\mathrm{b}}$} & $76.7^{\mathrm{c}}$ & 84.3 & 85.2 & 98.7 & 96.0 & 74.8 & 82.0 & 83.2 & 85.4 & 93.5 & 98.8 \\
& & $72.1^{\mathrm{d}}$ & 96.1 & 90.5 & 100 & 96.8 & 88.7 & 89.0 & 94.2 & 93.6 & 96.7 & \\
BYMV-IbG & \multirow{2}{*}{62.4} & 73.0 & 94.4 & 87.5 & 98.1 & 95.0 & 74.2 & 82.0 & 82.8 & 83.8 & 83.9 & 98.2 \\
& & 71.4 & 98.0 & 93.1 & 98.1 & 95.7 & 88.7 & 89.5 & 94.2 & 93.4 & 90.1 & \\
BYMV-GDD & \multirow{2}{*}{65.4} & 75.7 & 83.8 & 87.6 & 95.6 & 95.5 & 74.2 & 81.4 & 83.2 & 84.1 & 97.6 & 91.6 \\
& & 71.4 & 95.4 & 93.7 & 94.3 & 97.5 & 84.9 & 88.5 & 93.8 & 93.8 & 97.1 & \\
BYMV-S & \multirow{2}{*}{61.4} & 73.5 & 80.2 & 82.7 & 89.9 & 87.1 & 80.5 & 80.9 & 85.3 & 81.7 & 85.6 & 94.2 \\
& & 72.8 & 91.2 & 89.9 & 100 & 96.4 & 92.5 & 87.4 & 96.3 & 91.9 & 92.3 \\
\hline
\end{tabular}

${ }^{\mathrm{a}}$ GenBank accession numbers of BYMV isolates are as follows; BYMV-MB4 (D83749), BYMV-IbG (AB079887), BYMV-GDD (AY192568), BYMV-S (U47033) and BYMV-Fr (FJ492961, in this study).

${ }^{b}$ Numbers indicate percentage sequence identity.

${ }^{\mathrm{c}}$ The upper number represents sequence identity of nucleotides.

${ }^{\mathrm{d}}$ The lower number represents sequence identity of amino acids.

BYMV strains MB4, IbG, GDD and S, to identify overall and specific regions of aa sequence identity (Table 2). The comparisons revealed HC-pro, P3, 6K1, CI, NIa, $\mathrm{NIb}$ and $\mathrm{CP}$ were highly conserved among BYMV strains, ranging from 80.2 to $100 \%$ and the sequence identities of $\mathrm{P} 1,6 \mathrm{~K} 2$, and $\mathrm{VPg}$ were relatively lower, ranging from 71.4 to $92.5 \%$.

The complete genome sequence of BYMV-Fr was compared with those of 52 potyviruses including 4 BYMV strains deposited in the Genbank using computational sequence pairwise software such as MEGA5 and DNAMAN. Some of the isolates from same countries and same host that clustered together were skipped and only one representative sequence of potyviruses was chosen to simplify the phylogenetic tree analysis. Among the 52 potyviruses, the aa sequence of BYMV-Fr showed the highest identity with the aa sequence of clover yellow vein virus (ClYVV) in the prolyprotein (Fig. 2 and Fig. 3). Phylogenetic analysis of the aa sequence identity existing among BYMV strains and the $\mathrm{CP}$ products encoded by other potyviruses, revealed that potyvirus $\mathrm{CP}$ is the most highly conserved (Fig. 2), similar to results obtained from other potyvirus comparisons (Hammond and Hammond, 2003; Parrella and Lanave, 2009; Takahashi et al., 1990; Wylie et al., 2002; Wylie et al., 2008). In a phylogenetic tree analysis with CP aa sequences, BYMV strains were the most closest to ClYVV, though we did not find out any relationships between BYMV strains originating from different geographical regions or isolation host species (Fig. 2). Since BYMV isolates were divided into 4 pathotypes based on differential host reactions, which correlated with major subgroupings observed in phylogenetic trees based on CP aa or nt sequence (Wada, 2000). It is noteworthy that isolates MB4 and $\mathrm{S}$ both originated from broad bean, whereas GDD was isolated from gladiolus, so it will be of interesting if the biological properties of BYMV-Fr are different from those of other BYMV strains. Construction of an infectious cDNA clone of BYMV-Fr will be helpful of the substitution of portions of the genome of isolates differing in sequences to identity symptom determinants of BYMV.

The $5^{\prime} \mathrm{NCR}$ and 3 'NCR nt sequences of BYMV-Fr showed 21.9-51.2 and 24.5-36.5\% identities with those of other potyviruses, respectively (data not shown). To our knowledge, this is the first report of the complete genome sequence of BYMV freesia strain.

\section{Acknowledgments}

This study was supported by the Next Generation BioGreen21 Program (PJ007984042013 to JYY) of the Rural Development Administration, Republic of Korea. SHC was supported by a research grant from Seoul Women's University (2011).

\section{References}

Allison, R., Johnston, R. E. and Dougherty, W. G. 1986. The nucleotide sequence of the coding region of tobacco etch virus genomic RNA: evidence for the synthesis of a single polyprotein. Virology 154: 9-20.

Bos, L. 1970. Descriptions of Plant Viruses, Bean yellow mosaic virus, $\mathrm{CMI} / \mathrm{AAB}, \mathrm{UK}$.

Brunt, A. A. 1995. Virus and Virus-like Diseases of Bulb and Flower Crops. pp. 274-280. John Wiley \& Sons, UK.

Chang, C. A., Hiebert, E. and Purcifull, D. E. 1988a. Analysis of in vitro translation of Bean yellow mosaic virus RNA: Inhibition of proteolytic processing by antiserum to the $49 \mathrm{~K}$ nuclear inclusion protein. J. Gen. Virol. 69: 1117-1122.

Chang, C. A., Hiebert, E. and Purcifull, D. E. 1988b. Purification, characterization, and immunological analysis of nuclear 
inclusions induced by bean yellow mosaic and clover yellow vein potyviruses. Phytopathology 78: 1266-1275.

Derks, A. F. L. M., Vink-van den Abeele, J. L. and Muller, P. J. 1980. Bean yellow mosaic virus in some iridaceous plants. Acta Hort. 110: 31-37.

Dougherty, W. G., Cary, S. M. and Parks, T. D. 1989. Molecular genetic analysis of a plant virus polyprotein cleavage site: a model. Virology 171: 356-364.

Gal-On, A. 2000. A point mutation in the FRNK motif of the potyvirus helper component-protease gene alters symptom expression in cucurbits and elicits protection against the severe homologous virus. Phytopathology 90: 467-473.

Ganesh-Selvaraj, D. G., Pokorný, R. and Holková, L. 2009. Variability of Bean yellow mosaic virus isolates in the Czech Republic. Acta Virol. 53: 277-280.

Guyatt, K. J., Proll, D. F., Menssen, A. and Davidson, A. J. 1996. The complete nucleotide sequence of bean yellow mosaic potyvirus RNA. Arch. Virol. 141: 1231-1246.

Hammond, J. and Hammon, R. W. 2003. The complete nucleotide sequence of isolate BYMV-GDD of Bean yellow mosaic virus, and comparison to other potyviruses. Arch. Virol. 148: 2461-2470.

Kumar, Y., Hallan, V. and Zaidi, A. A. 2009. Identification and characterization of Bean yellow mosaic virus infecting freesia. J. Plant Biochem. Biotech. 18: 253-255.

Lopez-Moya, J. J., Wang, R. Y. and Pirone, T. P. 1999. Context of the coat protein DAG motif affects potyviurs transmissibility by aphids. J. Gen. Virol. 80: 3281-3288.

Magie, R. O. and Poe, S. L. 1972. Disease and pest associates of bulbs and plants. In: The World of Gladiolus, pp. 155-167. Edgewood Press, USA.

Parrella, G. and Lanave, C. 2009. Identification of a new pathotype of Bean yellow mosaic virus (BYMV) infecting blue passion flower and some evolutionary characteristics of BYMV. Arch. Virol. 154: 1689-1694.

Randle, R. W., Davies, C., Gibbs, A. J. and Hatta, T. 1980. Amino acid composition of capsid protein as a taxonomic criterion for classifying the atypical S strain of Bean yellow mosaic virus. Aust. J. Biol. Sci. 33: 243-254.

Shukla, D. D., Strike, P. M., Tracy, S. L., Gough, K. H. and Ward,
C. W. 1988. The $\mathrm{N}$ and $\mathrm{C}$ terminal of the coat protein Potyviruses are surface located and the N-terminus contains major virus specific epitopes. J. Gen. Virol. 69: 1497-1508.

Shukla, D. D., Ward, C. W. and Brunt, A. A. 1994. The Potyviridae. CAB International, UK, 516 pp.

Takahashi, T., Uyeda, I., Ohshima, K. and Shikata, E. 1990. Nucleotide sequence of the capsid protein gene of Bean yellow mosaic virus chlorotic spot strain. J. Fac. Agr. Hokkaido Univ. 64: 152-163.

Tamura, K., Peterson, D., Peterson, N., Stecher, G., Nei, M. and Kumar, S. 2011. MEGA5: Molecular evolutionary genetics analysis using maximum likelihood, evolutionary distance, and maximum parsimony methods. Mol. Biol. Evol. 28: 27312739.

Urcuqui-Inchima, S., Haenni, A. and Bernardi, F. 2001. Potyvirus proteins: a wealth of functions. Virus Res. 74: 157-175.

Vaira, A. M., Lisa, V., Costantini, A., Masenga, V., Rapetti, S. and Milne, R. G. 2006. Ophioviruses infecting ornamentals and a probable new species associated with a severe disease in freesia. Acta Hort. 722: 191-199.

Vance, V. B., Moore, D., Turpen, T. H., Bracker, A. and Hollowell, V. C. 1992. The complete nucleotide sequence of pepper mottle virus genomic RNA: comparison of the encoded polyprotein with those of other sequenced potyviruses. Virology 191: 19-30.

Wada, Y., Iwai, H., Ogawa, Y. and Arai, K. 2000. Comparison of pathogenicity and nucleotide sequences of 30-terminal regions of Bean yellow mosaic virus isolate from gladiolus. J. Gen. Plant Pathol. 66: 345-352.

Wang, L. 2006. Freesia. In: Flower Breeding and Genetics, ed. N. O. Anderson, pp. 665-693. Springer, The Netherlands.

Wylie, S. J., Kueh, J., Welsh, B., Smith, L. J., Jones, M. G. K. and Jones, R. A. C. 2002. A non-aphid-transmissible isolate of bean yellow mosaic potyvirus has an altered NAG motif in its coat protein. Arch. Virol. 147: 1813-1820.

Wylie, S. J., Coutts, B. A., Jones, M. G. K. and Jones, R. A. C. 2008. Phylogenetic analysis of Bean yellow mosaic virus isolates from four continents: Relationship between the seven groups found and their hosts and origins. Plant Dis. 92: 15961603. 